\title{
Characterization of AIN Inclusion Particles Formed in Commercial Purity Aluminum
}

\begin{abstract}
FENG WANG and ZHONGYUN FAN
The detailed characterization of nitride inclusion particles formed in the commercial purity $\mathrm{Al}$ melt has been carried out using advanced analytical electron microscopy assisted with pressure melt filtration and focused ion beam sample preparation techniques. It is found that the nitride inclusion particles have short rod-like morphology with an average length of $375 \mathrm{~nm}$ and an average width of $104 \mathrm{~nm}$. Moreover, these nitride particles are identified to be hexagonal wurtzite AlN particles with the most close-packed plane, $\{0001\}$, as the exposed broad plane. Based on the crystallographic information, the potency of AlN as nucleation substrate for $\alpha$-Al grain has been theoretically estimated from the lattice matching point of view. It is revealed that the interatomic spacing misfit along the close-packed directions on the close-packed planes between $\mathrm{AlN}$ and $\mathrm{Al}$ is $6.66 \mathrm{pct}$, indicating relatively strong potency of $\mathrm{AlN}$ as nucleation substrate for $\alpha$-Al. However, it is suggested that AlN particles would rarely be involved in the nucleation and initiation of $\alpha$-Al grains when competing with other oxide and boride inclusion particles normally present in the Al melt because AlN particles have larger misfit with $\mathrm{Al}$, comparable or even smaller size, and lower number density than oxides and borides.
\end{abstract}

https://doi.org/10.1007/s11661-019-05150-y

(C) The Author(s) 2019

\section{INTRODUCTION}

THE formation and entrainment of inclusions in $\mathrm{Al}$ alloy melts is inevitable during melting and casting processes due to the interactions with environment and atmosphere. Under normal conditions, these inclusions exist in the form of particles, films, and clusters/ agglomerates and are considered as defects affecting the production of $\mathrm{Al}$ alloys and detrimental to the performance of final products. It is found that inclusions are often associated with the casting defects such as porosity, hot tearing, and cracking process and lead to poor strength, ductility, machinability, and corrosion resistance of the castings. ${ }^{[1]}$ Therefore, enormous effort has been devoted to the maximum reduction of inclusions from the melt prior to casting. By far, a number of methods including flotation, filtration, sedimentation, and centrifugal and electromagnetic separation have been proposed to remove inclusions from the $\mathrm{Al}$ melt. ${ }^{[2-4]}$

Recently, however, it has been demonstrated that the inclusions can be uniformly dispersed throughout the volume of melt and be positively used as nucleation

FENG WANG and ZHONGYUN FAN are with the EPSRC Centre for LiME, BCAST, Brunel University London, Uxbridge, UB8 3PH, UK. Contact e-mail: feng.wang@ brunel.ac.uk

Manuscript submitted October 25, 2018.

Article published online February 25, 2019 substrates for the matrix phase or other primary solid phases via special melt treatment such as intensive melt shearing ${ }^{[5-9]}$ and high-intensity ultrasonication ${ }^{[10,11]}$ in $\mathrm{Al}$ and $\mathrm{Mg}$ alloys. Such dispersed inclusion particles enhance the heterogeneous nucleation of primary solid phase during solidification and promotes the refinement of the primary solid phase which eventually improves the properties of the castings. In theory, this method of harnessing inclusions as nucleation substrates for the primary solid phase provides a sustainable and economic solution to achieve grain refinement in $\mathrm{Al}$ alloys and offers an opportunity for the development of closed-loop recyclable $\mathrm{Al}$ alloys since no extra inoculation particles are required.

From either removal or utilization point of view, it is important to obtain the comprehensive details of all the inclusions formed and entrained in the Al melt. It is now generally recognized that the major constituent of the inclusions in $\mathrm{Al}$ melt are the oxides. ${ }^{[12-14]}$ There are mainly amorphous $\mathrm{Al}_{2} \mathrm{O}_{3}, \gamma-\mathrm{Al}_{2} \mathrm{O}_{3}, \alpha-\mathrm{Al}_{2} \mathrm{O}_{3}, \mathrm{MgAl}_{2} \mathrm{O}_{4}$, and $\mathrm{MgO}$ that present in the form of particles, agglomerates, and/or films depending on the specific conditions such as melt temperature, alloy composition, pouring atmosphere, and holding/handling time. The formation mechanisms, behavior in the Al melt after entrainment, morphology, and crystallography features of the oxides have been extensively investigated and are readily available in the literature. ${ }^{[15-22]}$ Other common inclusions include carbides, borides, nitrides, chlorides, and fluorides. ${ }^{[12]}$ Among these, nitrides are one type of the 
inclusions that are considered as potential candidates of nucleation substrates for $\alpha$-Al grains ${ }^{[23]}$ and yet few details are available in the literature. It has been reported that nitrides form by the reaction between the melt and atmosphere where the partial pressure of oxygen is locally reduced due to the reaction between melt and oxygen. ${ }^{[21,24-26]}$ One typical source of such particular atmosphere is the one trapped in the double oxide film entrained in the Al melt as well described by Griffiths et al. ${ }^{[25,26]}$ Although the nitrides have been identified by X-ray diffraction (XRD) to be AlN and an acicular morphology has been observed using scanning electron microscopy (SEM), ${ }^{[21,26]}$ the essential information regarding the detailed morphological and crystallographic features is scarce. This information is prerequisite for understanding the role of nitride particles in solidification of Al alloys. One major reason for the lack of such information for these inclusion particles is their low concentration (up to $20 \mathrm{ppm})^{[12]}$ normally present in the Al melt which imposes great difficulty to prepare proper samples for advanced characterization.

In the present work, the detailed morphological and crystallographic characteristics of the nitride particles formed in the commercial purity $\mathrm{Al}$ melt have been determined by using analytical electron microscopy assisted with the pressure melt filtration and focused ion beam (FIB) sample preparation techniques. Furthermore, the potency of the nitride particles as nucleation substrate for $\alpha$-Al solid has been theoretically evaluated and compared with the other inclusion particles from the lattice matching point of view. In the end, the possible role of nitride particles in facilitating heterogeneous nucleation of $\alpha$-Al grains and promoting grain refinement of $\alpha$-Al grains is discussed.

\section{EXPERIMENTAL}

Commercial purity $\mathrm{Al}$ ingot (approximately $2 \mathrm{~kg}$ for each experiment) was put in a clay-bonded graphite crucible coated with boron nitride and melted inside an electrical resistance furnace at $750{ }^{\circ} \mathrm{C}$ and $850^{\circ} \mathrm{C}$, respectively. After being held at the corresponding temperature for around 1 hour, the melt was poured into a pre-heated filtration crucible which was then transferred to and locked in the chamber of the pressure filtration equipment $\left(\right.$ Prefil $^{\circledR}$-Footprinter, ABB). Following that, argon gas was introduced into the chamber to pressure the melt through the porous ceramic filter fixed at the bottom of the filtration crucible. While the melt passed through the filter, inclusions were collected and concentrated on top of the filter. As the remaining Al melt solidified, the samples were taken from the position close to the top of the filter and then mounted, grinded, and polished for examination. The details of the pressure melt filtration equipment and principles can be found elsewhere. ${ }^{[27]}$

The detection of the inclusions collected in the samples was first carried out in a dual-beam (FIB and SEM) microscope (Crossbeam 340, ZEISS) equipped with an energy dispersive X-ray spectroscopy (EDS) system (Octane Elite EDS System, EDAX). Nitride particles were located via both morphology and composition analysis using the SEM and EDS at $5 \mathrm{kV}$. In order to further examine these nitride particles in transmission electron microscope (TEM), thin foil samples containing these particles were prepared in situ by FIB. The nitride particles were cut and lift out by a tungsten manipulator and transferred to the Omni lift-out copper grids which are specially designed for the TEM sample holder. After the transfer, the relatively thick (approximately $300 \mathrm{~nm}$ ) foils on the $\mathrm{Cu}$ grid were further thinned using the FIB step by step to around $50 \mathrm{~nm}$. The thin foils were then investigated in a JEOL $2100 \mathrm{~F}$ TEM at $200 \mathrm{kV}$.

\section{RESULTS}

Before the detailed characterization of nitride inclusion particles is presented, it is necessary to mention here that, during the examination of the samples using SEM, the most-commonly found inclusion particles are oxide particles with their composition confirmed by EDS analysis. Figure 1 shows the typical oxide inclusion particles observed in the samples and the corresponding EDS spectra. This high frequency of finding oxide inclusion particles agrees with the fact that the oxide inclusions are the major constituent of the inclusions formed in the $\mathrm{Al}$ melts as reported in the literature. ${ }^{[12-14]}$ In contrast, it required great effort to locate the nitride inclusions particles even in these samples with concentrated inclusions after pressure melt filtration.

Figures 2(a) and 2(b) show the typical nitride inclusion particles detected in the samples after the corresponding Al melt had been held at $750{ }^{\circ} \mathrm{C}$ and $850{ }^{\circ} \mathrm{C}$, respectively. As we can see, most of the nitride particles display short rod-like morphology on the sample cross sections and seem quite similar to the $\alpha-\mathrm{Al}_{2} \mathrm{O}_{3}$ inclusion particles that were reported in the literature. ${ }^{[22]}$ However, the EDS spectra (Figure 2(c)) reveal that these particles contain high content of $\mathrm{N}$ and low content of $\mathrm{O}$ which indicates that they are not oxide particles but probably nitride particles. Note that the carbon peak of the EDS spectra is attributed to the electron beam-induced carbon deposition on the sample cross sections. The similar morphology between nitride and $\alpha-\mathrm{Al}_{2} \mathrm{O}_{3}$ particles may have made the previous distinction of nitride particles from $\alpha-\mathrm{Al}_{2} \mathrm{O}_{3}$ particles difficult based on only morphology difference using optical microscope $^{[18,19]}$ or SEM without EDS analysis. Careful observation finds that some of the nitride particles display platelet morphology as circled in Figure 1 (Spot No. 2, 4, 7, and 8), implying that the morphology of the nitride particles could be platelet rather than short rod as the short rod-like morphology may only represent the morphology on the 2D cross sections. Detailed FIB-3D tomography characterization is still underway to study the possible difference in aspect ratio of nitride particles formed in the melts of different holding temperatures and the results will be published in another paper. 

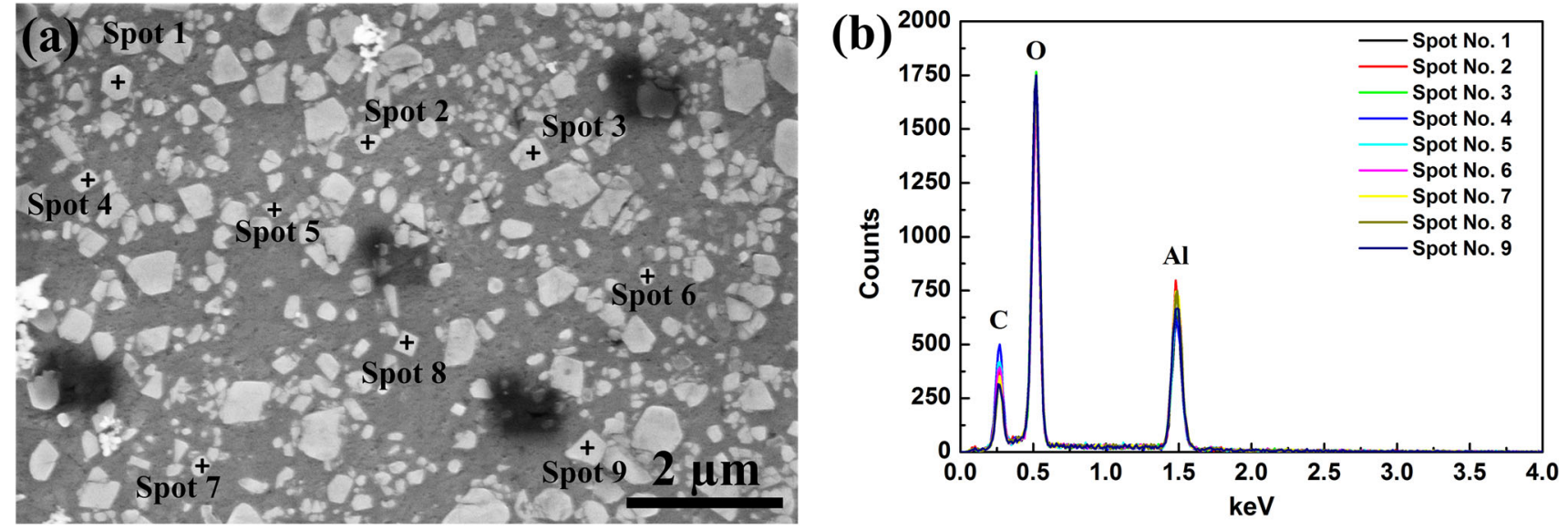

Fig. 1-(a) SEM secondary electron (SE) image of the typical oxide inclusion particles observed in the samples and (b) the EDS spectra from the corresponding particles marked by the numbers in (a).
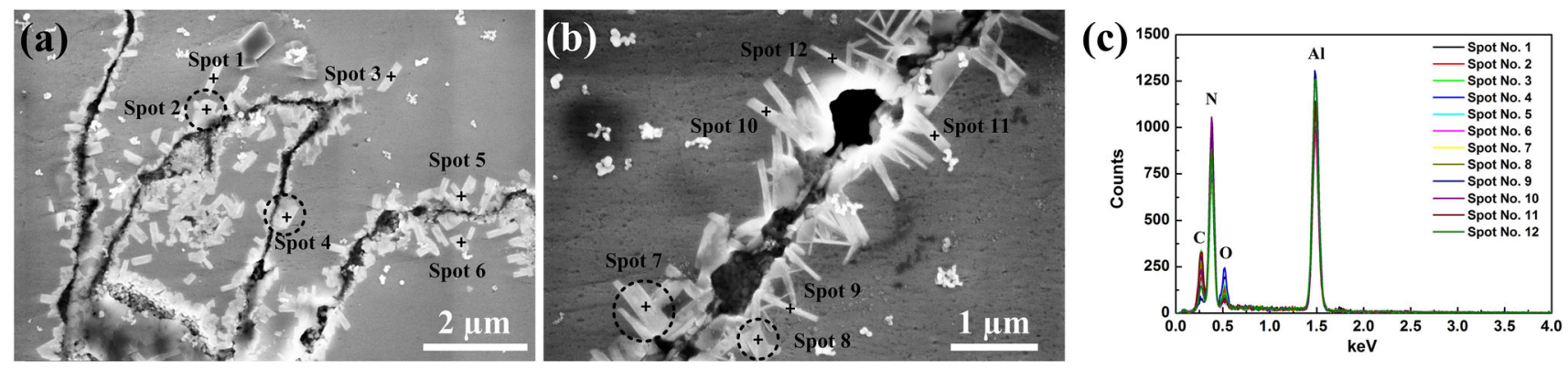

Fig. 2-SEM SE images of typical nitride inclusion particles detected in the samples solidified from the melt being held at $(a) 750{ }^{\circ} \mathrm{C}$ and $(b) 850$ ${ }^{\circ} \mathrm{C}$ and $(c)$ the EDS spectra from the corresponding particles marked by the numbers in (a) and (b).

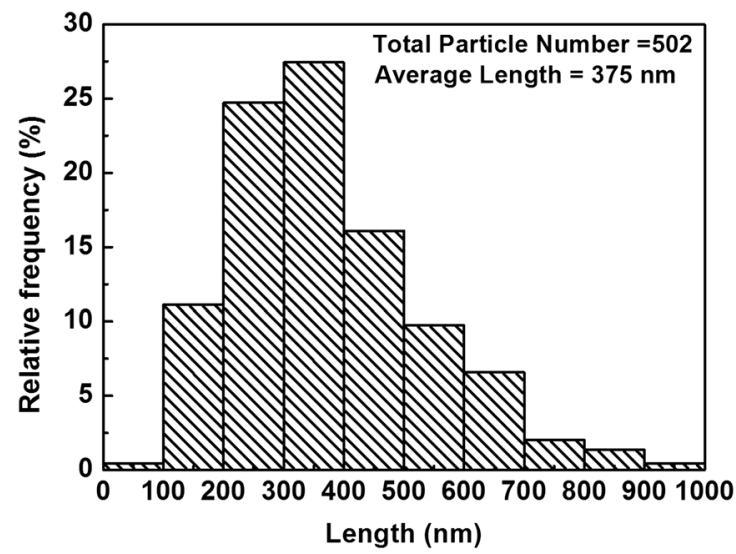

(a)

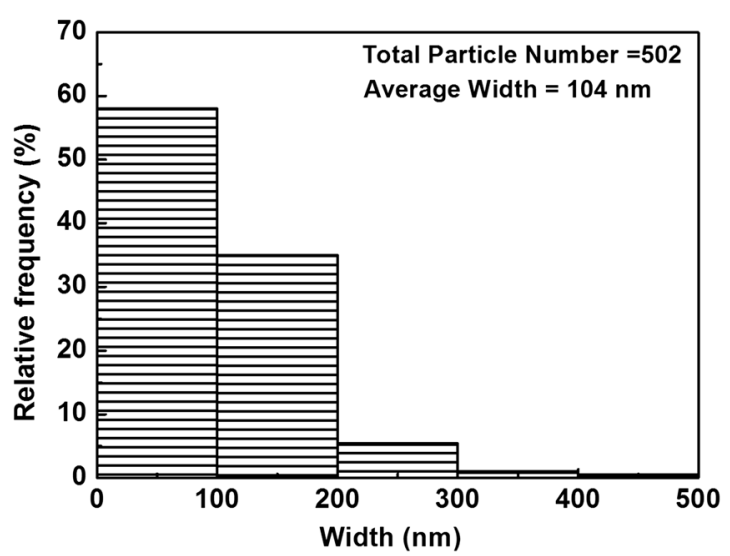

(b)

Fig. 3-Size distributions of nitride particles: $(a)$ length dimension and $(b)$ width dimension.

Based on the SEM micrographs, the length and width dimensions of the nitride particles observed in the present work were measured and the size distribution is shown in Figure 3. It is necessary to mention that the total number of nitride particles measured was only 502 which is the sum of all the examined samples with holding temperatures both at $750{ }^{\circ} \mathrm{C}$ and $850{ }^{\circ} \mathrm{C}$. This is because it was difficult to spot the nitride particles on the cross sections of samples due to the small quantity of nitride particles even though concentration had been done by pressure filtration. In addition, little difference in the size distribution could be detected between the samples of different holding temperatures in the current study and hence all the data are plotted in one figure, Figure 3. It is clear that the size distribution of length dimension is generally in log-normal form with average 
length around $375 \mathrm{~nm}$, while the size distribution of width dimension is more likely in the right half of the log-normal distribution with the average width around $104 \mathrm{~nm}$. The peculiar size distribution of width dimension probably originates from the fact that the image analysis based on the SEM micrographs was not able to accurately measure width smaller than $100 \mathrm{~nm}$. Despite the statistical limitation regarding the total number and the width measurement, it is found that the nitride particles formed in the present work are much smaller than those reported in the literature. ${ }^{[21,26]}$ This discrepancy may arise from the difference in the melting conditions, particularly the melt temperature and holding time.

As described in the experimental section, the possible nitride particles detected by SEM were cut out and thinned to foils by FIB for TEM examination. A typical dark-field (DF) scanning TEM (STEM) image of the particles and the corresponding EDS mapping are shown in Figure 4. As we can see from the element distributions, it is manifest that the particles are rich in $\mathrm{N}$ with little $\mathrm{O}$ inside as the distribution of $\mathrm{O}$ element, Figure 4(d), is roughly uniform across the whole foil sample. The peak of $\mathrm{O}$ in the EDS spectra obtained in SEM may come from the electron beam interaction volume that probably contains some oxide inside. This problem was avoided due to the small thinness (around $50 \mathrm{~nm}$ ) of the foil samples. However, the electron beam-induced carbon deposition still occurred on the foil samples as shown in Figure 4(e). Despite this, the EDS mapping confirms that the particles are nitride particles.
Although the crystal structure of nitride particles have been previously identified by XRD to be AIN with stable hexagonal wurtzite structure, ${ }^{[21,26]}$ it is still necessary to confirm the crystal structure of the nitride particles observed in the present work. This is because there is great difference in the size of the nitride particles presented in the current and previous work. ${ }^{[21,26]}$ Moreover, Griffiths et al. ${ }^{[28]}$ recently reported that there are extreme conditions occurring in the interior atmosphere trapped between double oxide film and these extreme conditions may cause the formation of A1N with metastable crystal structure such as cubic zinc-blende or rock-salt structures. As a consequence, the crystal structure was further determined by selected area diffraction analysis on the nitride particles observed in the present work. In total, 30 nitride particles from samples with holding temperatures both at $750{ }^{\circ} \mathrm{C}$ and $850{ }^{\circ} \mathrm{C}$ have been examined. It was found that all the SADPs obtained from the nitride particles formed in both melts held at $750{ }^{\circ} \mathrm{C}$ and $850{ }^{\circ} \mathrm{C}$ could be consistently indexed as hexagonal wurtzite AIN. For brevity, only a typical series of selected area diffraction patterns (SADPs) at different tilting angles of one nitride particle are presented in Figure 5. Moreover, the measured values of d-spacings agree well with the published values of hexagonal wurtzite AIN as shown in Table I. ${ }^{[29]}$ In addition, it could be roughly deduced that the exposed broad plane of the AIN particles is the $\{0001\}$ plane by overlapping the BF TEM image and the diffraction pattern at the same beam directions such as $[2 \overline{1} \overline{1} 0]$ direction.
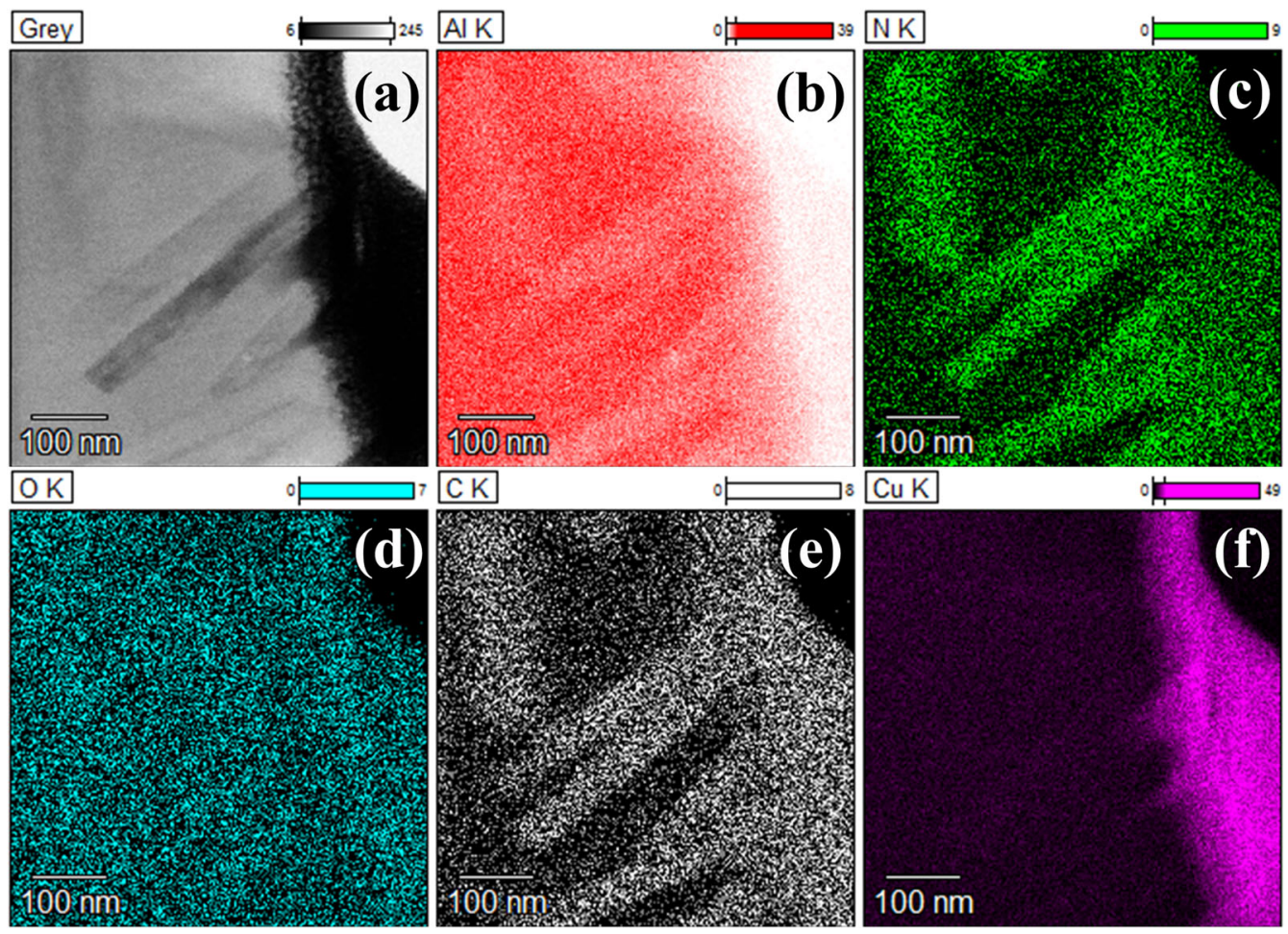

Fig. 4 - (a) Dark-field STEM image of a foil sample containing nitride particles that were detected by SEM and the corresponding EDS mapping of $(b) \mathrm{Al}$ element, $(c) \mathrm{N}$ element, $(d) \mathrm{O}$ element, $(e) \mathrm{C}$ element, and $(f) \mathrm{Cu}$ element distributions across the sample. 

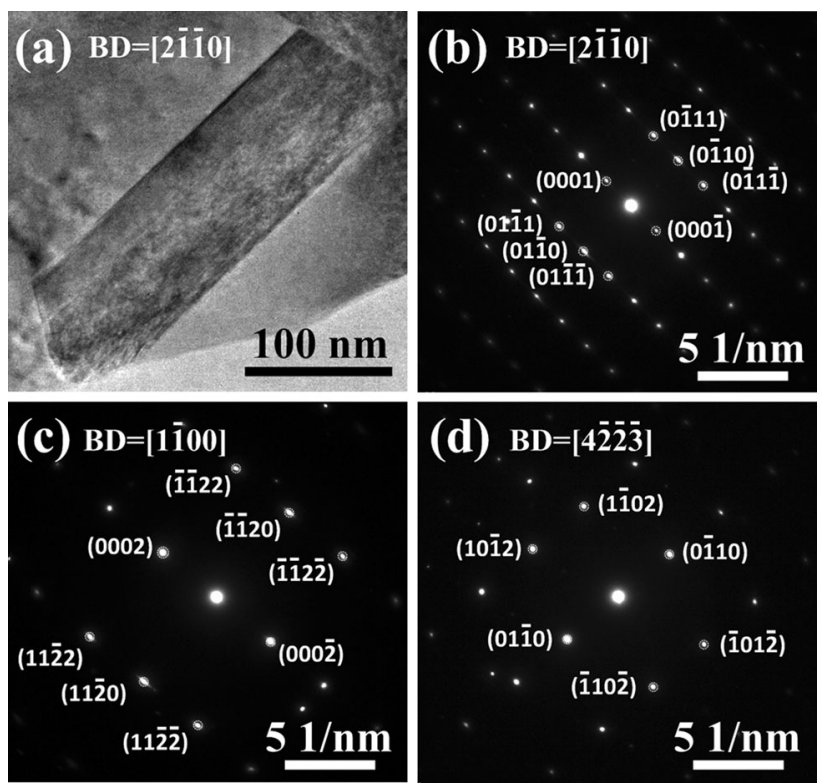

Fig. 5- (a) TEM bright field image of a typical nitride particle with electron beam direction along $[21 \overline{1} 0] ;(b)$ through $(d)$ the SADPs obtained from the nitride particle and indexed as hexagonal wurtzite AlN with electron beam directions along (b) $[2 \overline{1} \overline{1} 0]$, (c) $[1 \overline{1} 00]$, and (d) $[4 \overline{2} \overline{2} \overline{3}]$.

Table I. Comparison Between the Values of Measured and Calculated $d$-Spacing of $\mathrm{AlN}^{[29]}$

\begin{tabular}{lcc}
\hline Plane & $\begin{array}{c}\text { Measured } d \text {-Spacing } \\
(\mathrm{nm})\end{array}$ & $\begin{array}{c}\text { Calculated } d \text {-Spacing } \\
(\mathrm{nm})\end{array}$ \\
\hline$(0001)$ & 0.5099 & 0.4980 \\
$(01 \overline{1} 0)$ & 0.2748 & 0.2693 \\
$(01 \overline{1} 1)$ & 0.2401 & 0.2369 \\
$(11 \overline{2} 0)$ & 0.1603 & 0.1555 \\
$(11 \overline{2} 2)$ & 0.1370 & 0.1319 \\
$(10 \overline{1} 2)$ & 0.1834 & 0.1828 \\
\hline
\end{tabular}

In order to further determine the crystallographic plane of the exposed broad plane of the AlN particles, high-resolution (HR) TEM images were taken on the AIN particles. Figure 6 shows the HR TEM images of two representative AlN particles. Based on the measured $\mathrm{d}$-spacing of the lattice plane, it is found that the exposed broad plane of the AlN particles belongs to the $\{0001\}$ plane. This is consistent with the common crystal growth theory ${ }^{[30]}$ that the crystal is often bounded by the slowest-growing crystallographic plane which normally is the densest crystallographic plane due to the atomic attachment kinetics. In the case of hexagonal wurtzite AlN, the densest and hence the slowest-growing crystallographic plane is the $\{0001\}$ plane according to the crystal structure and atomic positions. ${ }^{[29]}$

In summary, the TEM results substantiate that the nitride inclusion particles formed in the present work are the hexagonal wurtzite AlN particles with $\{0001\}$ plane as the exposed broad plane.

\section{DISCUSSION}

It is widely accepted that good crystallographic matching between the substrate and the nucleating solid favors the formation of a low-energy interface between them and hence can initiate the heterogeneous nucleation at small undercooling, indicating strong potency of the particle as nucleation substrate for the nucleating solid. Therefore, the potency of AIN particles as nucleation substrate for $\alpha$-Al grain can be theoretically evaluated by calculating the crystallographic matching between them. In fact, an attempt to estimate the crystallographic matching between AlN particles and Al had been recently made by Liu et al. but a cubic crystal structure of AlN was used in their calculation. ${ }^{[31]}$ This is different from the AlN particles in the present work that have hexagonal wurtzite crystal structure as experimentally determined in the above section. Figure 7(a) shows the atomic configuration on the exposed broad plane, (0001), of hexagonal wurtzite AlN. It is necessary to point out that the $\mathrm{Al}$ atoms and $\mathrm{N}$ atoms are not exactly on the same plane as $\mathrm{N}$ atomic plane are actually $0.0587 \mathrm{~nm}$ below the $\mathrm{Al}$ atomic plane with the same arrangement. For simplicity, only the $\mathrm{Al}$ atomic plane will be considered in the following calculation. Furthermore, the exposed (0001) plane of AlN is the most close-packed plane which contains the most closepacked direction $\langle 2 \overline{1} \overline{1} 0\rangle$. It is noticed that the atomic configuration on $(0001)_{\text {AIN }}$ plane is similar to the most close-packed plane of $\mathrm{Al},(111)_{\mathrm{Al}}$, as presented in Figure 7(b). The detailed crystallographic data of AlN, $\mathrm{Al}$, and other common oxide and boride phases are listed in Table II. ${ }^{[22,29]}$

Based on the data, the interatomic spacing misfit, $f_{\mathrm{r}}$, along the most close-packed directions and the interplanar misfit, $f_{\mathrm{d}}$, of the most close-packed planes between the particles and Al can be calculated using the following equations ${ }^{[32]}$ :

$$
\begin{aligned}
& f_{\mathrm{r}}=\frac{\left|r_{\mathrm{Al}}-r_{\mathrm{P}}\right|}{r_{\mathrm{P}}} \times 100 \mathrm{pct}, \\
& f_{\mathrm{d}}=\frac{\left|d_{\mathrm{Al}}-d_{\mathrm{P}}\right|}{d_{\mathrm{P}}} \times 100 \mathrm{pct},
\end{aligned}
$$

where $r_{\mathrm{Al}}$ and $r_{\mathrm{P}}$ are the interatomic spacings along the most close-packed direction, while $d_{\mathrm{Al}}$ and $d_{\mathrm{p}}$ are the interplanar spacings of the most close-packed plane of $\mathrm{Al}$ and particles, respectively. Note that the $r_{\mathrm{P}}$ and $d_{\mathrm{p}}$ are chosen for the denominators for calculation as explained by Qiu et al. ${ }^{[32]}$ As we can see in Table II, all the values of the calculated interatomic spacing misfit, $f_{\mathrm{r}}$, between $\mathrm{Al}$ and the particles are smaller than $7 \mathrm{pct}$, indicating they are all potent nucleating substrates for $\alpha$-Al grains, i.e., can initiate heterogeneous nucleation of $\alpha$-Al grains at small undercooling. However, it is found that AlN has the largest interatomic spacing misfit with $\mathrm{Al}$ compared to other common oxides and borides present in the $\mathrm{Al}$ melts, implying that AlN would be the last one to start the heterogeneous nucleation since it requires larger undercooling when competing with other 

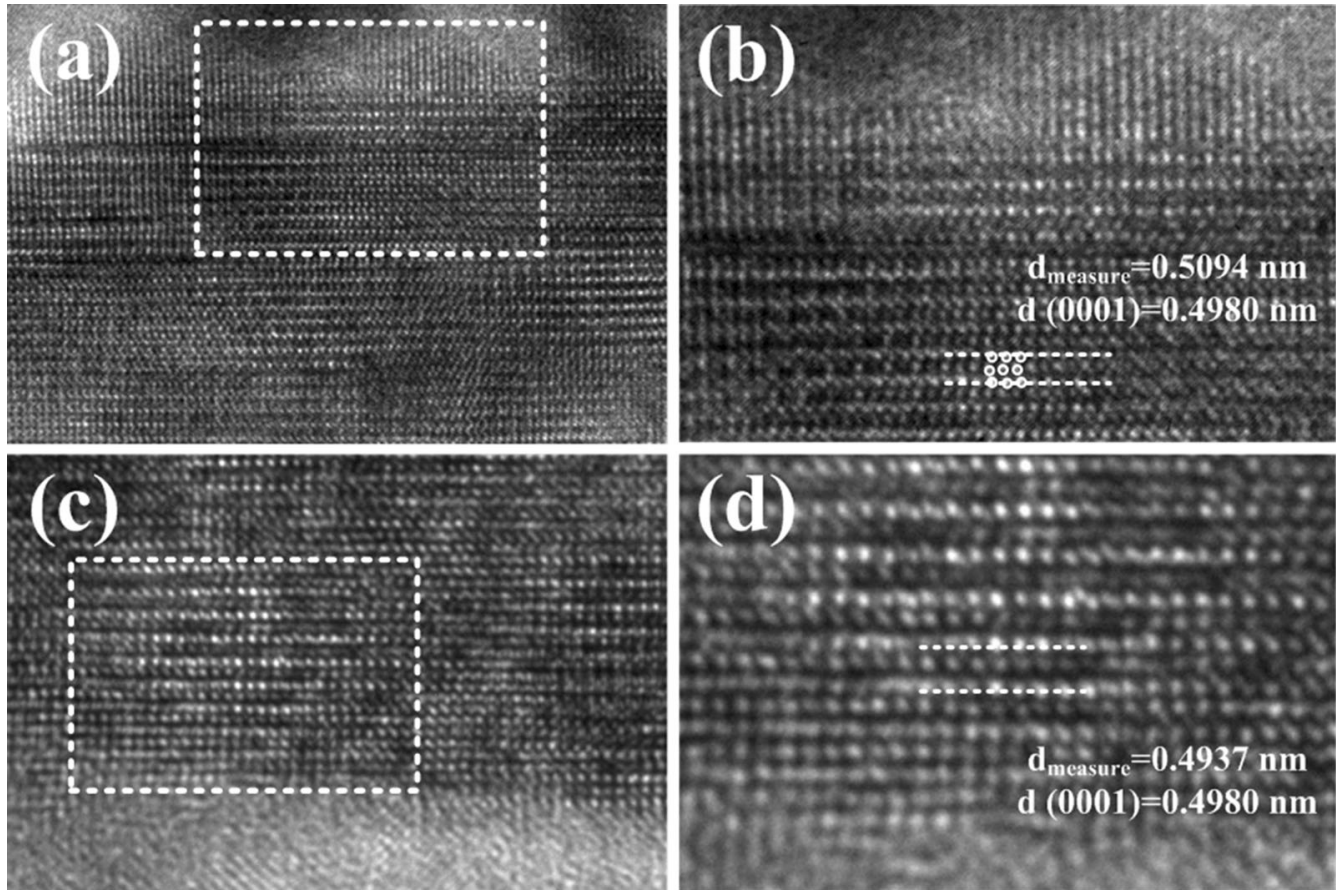

Fig. 6-HR TEM images of two representative AlN particles $(a)$ and $(c)$ and the corresponding enlarged parts of the broad planes $(b)$ and $(d)$ revealing lattice configurations. The electron beam directions for both AlN particles were along [2110].

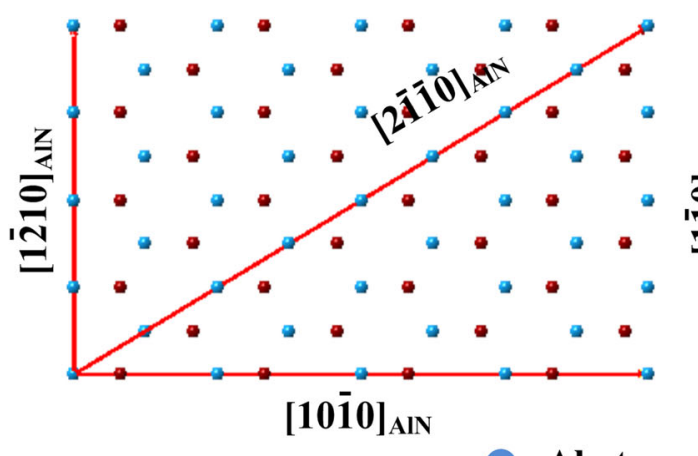

(a)

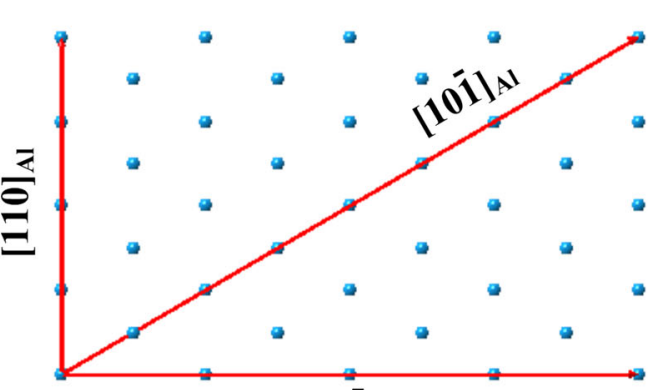

$[11 \overline{2}]_{\mathrm{Al}}$

$\mathbf{N}$ atom

(b)

Fig. 7-Atomic configurations on (a) (0001) plane of AlN and (b) (111) plane of Al with close-packed directions highlighted.

inclusion particles from the crystallographic matching point of view.

In addition to the crystallographic matching, the size of the substrate particles also plays a critical role in the initiation of $\alpha$-Al grains according to the free growth model. $^{[34]}$ It proposes that the bigger the substrate particles are, the more potent they are. From this perspective, however, AlN particles are still unfavorable because the AlN particles (length dimension on submicron scale with average size around $0.375 \mu \mathrm{m}=$ $375 \mathrm{~nm}$, Figure 3) observed in the present work have comparable or even smaller size with the oxides (submicron scale $)^{[22,35]}$ and borides (submicron scale with average particle size around 0.67 to $0.72 \mu \mathrm{m}=670$ to $720 \mathrm{~nm})^{[34,36]}$ reported in the previous studies.

Furthermore, it has been reported by Simensen and $\operatorname{Berg}^{[12]}$ that the amount of nitrides (3 to
$12 \mathrm{ppm}$ ) is similar to that of oxides (6 to $16 \mathrm{ppm}$ ) in commercial Al. Considering that nitride particles also have similar size, morphology, and density with oxide particles, they should have similar number in commercial Al. However, it was noticed that the chance of spotting AlN particles was much lower than spotting oxide particles during the examination of the samples in the present work, implying that the number density of AlN particles is probably much lower than that of oxide particles in the present work. The reason for this still requires further investigation. Nevertheless, the low number density of AlN particles observed in the present work further reduces the possibility of them acting as nucleating substrates for $\alpha$-Al grains during the solidification of Al melt in which other inclusion particles including oxide particles also exist. 
Table II. Crystallographic Data of Al, AIN, and Common Oxides and Borides at $660^{\circ} \mathrm{C}^{[22,33]}$

\begin{tabular}{|c|c|c|c|c|c|c|c|c|c|}
\hline \multirow[b]{2}{*}{ Phase } & \multirow[b]{2}{*}{ Structure } & \multicolumn{2}{|c|}{ Lattice Parameter } & \multirow{2}{*}{$\begin{array}{l}\text { Close-Packed } \\
\text { Plane }\end{array}$} & \multirow{2}{*}{$\begin{array}{l}\text { Close-Packed } \\
\text { Row }\end{array}$} & \multirow[b]{2}{*}{$d_{(h k l)}(\mathrm{nm})$} & \multirow[b]{2}{*}{$f_{\mathrm{d}}(\mathrm{Pct})$} & \multirow[b]{2}{*}{$r_{[u v w]} \mathrm{nm}$} & \multirow[b]{2}{*}{$f_{\mathrm{r}}(\mathrm{Pct})$} \\
\hline & & $a$ & $c$ & & & & & & \\
\hline $\mathrm{Al}$ & cubic & 0.4121 & - & $\{111\}$ & $\langle 110\rangle$ & $\begin{array}{r}\{111\} \\
0.2379\end{array}$ & $\mathrm{~N} / \mathrm{A}$ & 0.2914 & $\mathrm{~N} / \mathrm{A}$ \\
\hline AlN & hexagonal & 0.3122 & 0.4992 & $\{0001\}$ & $\langle 2 \overline{1} \overline{1} 0\rangle$ & $\begin{array}{l}\{0002\} \\
0.2496\end{array}$ & 4.67 & 0.3122 & 6.66 \\
\hline$\gamma-\mathrm{Al}_{2} \mathrm{O}_{3}$ & cubic & 0.7963 & - & $\{111\}$ & $\langle 110\rangle$ & $\begin{array}{r}\{222\} \\
0.2299\end{array}$ & 3.50 & 0.2815 & 3.50 \\
\hline$\alpha-\mathrm{Al}_{2} \mathrm{O}_{3}$ & rhomb. & 0.4782 & 1.3057 & $\{0001\}$ & $\langle 1 \overline{1} 00\rangle$ & $\begin{array}{c}\{0006\} \\
0.2176\end{array}$ & 9.33 & 0.2761 & 5.54 \\
\hline $\mathrm{MgAl}_{2} \mathrm{O}_{4}$ & cubic & 0.8126 & - & $\{111\}$ & $\langle 110\rangle$ & $\begin{array}{r}\{222\} \\
0.2346\end{array}$ & 1.43 & 0.2873 & 1.43 \\
\hline $\mathrm{TiB}_{2}$ & hexagonal & 0.3037 & 0.3237 & $\{0001\}$ & $\langle 2 \overline{1} \overline{1} 0\rangle$ & $\begin{array}{c}\{0001\} \\
0.3237\end{array}$ & 26.49 & 0.3037 & 4.05 \\
\hline
\end{tabular}

From the above discussion, it is concluded that the AlN particles naturally formed in the Al melt have relatively weak potency as nucleating substrates for $\alpha$-Al when competing with other common inclusion particles, particularly oxide and boride particles. It is hence proposed that the AlN particles can hardly be involved in the nucleation and initiation of $\alpha$-Al grains during the solidification of $\mathrm{Al}$ melts.

\section{CONCLUSIONS}

The main findings are summarized as follows:

1. The nitride inclusion particles formed in commercial purity Al have short rod-like morphology with an average length of $375 \mathrm{~nm}$ and an average width of $104 \mathrm{~nm}$.

2. The nitride inclusion particles are identified to be hexagonal wurtzite AIN particles with the most close-packed plane, $\{0001\}$, as the exposed broad plane.

3. Theoretical crystallographic matching calculation reveals that the interatomic spacing misfit along the close-packed directions on the close-packed planes between $\mathrm{AlN}$ and $\mathrm{Al}$ is $6.66 \mathrm{pct}$, which indicates that AIN particles can act as relatively potent nucleation substrates for $\alpha$-Al.

4. It is proposed, however, that AlN particles would hardly be involved in the nucleation and initiation of $\alpha$-Al grains when competing with other oxide and boride inclusion particles normally present in the $\mathrm{Al}$ melt because AlN particles have larger misfit with Al, comparable or even smaller size, and lower number density than oxides and borides.

\section{ACKNOWLEDGMENTS}

The authors acknowledge the financial support from the UK government's Engineering and Physical Science Research Council (EPSRC) for Innovative Manufacturing in Liquid Metal Engineering (LiME) Centre.
The authors also thank Mr. Shihao Wang, Dr. Yijie Zhang, and Mr. Peter Lloyd for their assistance with casting and pressure melt filtration experiments.

\section{OPEN ACCESS}

This article is distributed under the terms of the Creative Commons Attribution 4.0 International License (http://creativecommons.org/licenses/by/4.0/), which permits unrestricted use, distribution, and reproduction in any medium, provided you give appropriate credit to the original author(s) and the source, provide a link to the Creative Commons license, and indicate if changes were made.

\section{REFERENCES}

1. J. Campbell: Castings, 2nd ed., Butterworth-Heinemann, Oxford, 2003.

2. F. Frisvold, T.A. Engh, S.T. Johansen, and T. Pedersen: Essent. Read. Light Met., 2013, vol. 3, pp. 324-31.

3. M.A. Dewan, M.A. Rhamdhani, J.B. Mitchell, C.J. Davidson, G.A. Brooks, M. Easton, and J.F. Grandfield: Mater. Sci. Forum, 2011, vol. 693, pp. 149-60.

4. X. Cao, J. Campbell: Advances in Aluminum Casting Technology II, 2002, vol. pp. 135-46.

5. Z. Fan, Y. Wang, M. Xia, and S. Arumuganathar: Acta Mater., 2009, vol. 57, pp. 4891-4901.

6. Z. Fan, Y. Wang, Z.F. Zhang, M. Xia, H.T. Li, J. Xu, L. Granasy, and G.M. Scamans: Int. J. Cast Met. Res., 2009, vol. 22, pp. $318-22$.

7. W. Khalifa, F.H. Samuel, and J.E. Gruzleski: Metall. Mater. Trans. A, 2004, vol. 35A, pp. 3233-50.

8. H.T. Li, Y. Wang, and Z. Fan: Acta Mater., 2012, vol. 60, pp. $1528-37$.

9. H.T. Li, M. Xia, P. Jarry, G.M. Scamans, and Z. Fan: J. Cryst. Growth, 2011, vol. 314, pp. 285-92.

10. F. Wang, D. Eskin, T. Connolley, C. Wang, B. Koe, A. King, C. Reinhard, and J. Mi: Mater. Lett., 2018, vol. 213, pp. 303-05.

11. F. Wang, D. Eskin, J. Mi, T. Connolley, J. Lindsay, and M. Mounib: Acta Mater., 2016, vol. 116, pp. 354-63.

12. C.J. Simensen and C. Berg: Alum. Dusseldorf, 1980, vol. 56, pp. 335-40.

13. Y. Birol: Int. J. Cast Met. Res., 2010, vol. 23, pp. 250-55.

14. S.W. Hudson and D. Apelian: Int. J. Metalcast., 2016, vol. 10, pp. 315-21.

15. C.N. Cochran, D.L. Belitskus, and D.L. Kinosz: Metall. Trans. B, 1977, vol. 8B, pp. 323-32. 
16. S.A. Impey, D.J. Stephenson, and J.R. Nicholls: Mater. Sci. Technol. (UK), 1988, vol. 4, pp. 1126-32.

17. E Bergsmark, CJ Simensen, and P Kofstad: Mater. Sci. Eng. A, 1989, vol. 120, pp. 91-95.

18. L. Liu and F.H. Samuel: J. Mater. Sci., 1997, vol. 32, pp. 5927-44.

19. L. Liu and F.H. Samuel: J. Mater. Sci., 1997, vol. 32, pp. 5901-25.

20. F.H. Samuel, P. Ouellet, and A. Simard: Int. J. Cast Met. Res., 1999, vol. 12, pp. 17-33.

21. K.L. More, P.F. Tortorelli, L.R. Walker, J. Hryn, and G. Krumdick: Mater. High Temp., 2003, vol. 20, pp. 453-60.

22. Y. Wang, H.T. Li, and Z. Fan: Trans. Ind. Inst. Met., 2012, vol. 65 , pp. $653-61$.

23. C. Borgonovo and M.M. Makhlouf: Metall. Mater. Trans. A, 2016, vol. 47A, pp. 1818-27.

24. S. Shivkumar, L. Wang, and D. Apelian: JOM, 1991, vol. 43, pp. 26-32.

25. W.D. Griffiths and R. Raiszadeh: J. Mater. Sci., 2009, vol. 44, pp. $3402-07$.

26. R. Raiszadeh and W.D. Griffiths: Metall. Mater. Trans. B, 2006, vol. 37B, pp. 865-71.

27. ABB, Prefil ${ }^{\circledR}-$ Footprinter Pressure filtration melt cleanliness analyzer: a quick and thorough inclusion control solution. (ABB, 2009) https://search-ext.abb.com/library/Download.aspx?Docume
ntID $=\mathrm{PB} \%$ 2fPrefilFootprinter-EN\&LanguageCode $=$ en $\&$ Docu mentPartId $=$ \&Action $=$ Launch. Accessed 25 Oct 2018 .

28. W.D. Griffiths, A. Elsayed, and M.A. El-Sayed: Metall. Mater. Trans. B, 2016, vol. 47B, pp. 3459-68.

29. H. Schulz and K.H. Thiemann: Solid State Commun., 1977, vol. 23, pp. 815-19.

30. K.A. Jackson: J. Cryst. Growth, 1968, vols. 3-4, pp. 507-17.

31. Y. Liu, Y. Huang, Z. Xiao: J. Mater. Res., 2017, vol. pp. 1-8.

32. D. Qiu, J.A. Taylor, and M.X. Zhang: Metall. Mater. Trans. A, 2010, vol. 41A, pp. 3412-21.

33. W.M. Yim and R.J. Paff: J. Appl. Phys., 1974, vol. 45, pp. $1456-57$.

34. A.L. Greer, A.M. Bunn, A. Tronche, P.V. Evans, and D.J. Bristow: Acta Mater., 2000, vol. 48, pp. 2823-35.

35. H.T. Li, Y. Wang, and Z. Fan, Enhanced heterogeneous nucleation on oxides in Al alloys by intensive shearing, IOP Conference Series: Materials Science and Engineering, 2011.

36. T.E. Quested and A.L. Greer: Acta Mater., 2005, vol. 53, pp. 4643-53.

Publisher's Note Springer Nature remains neutral with regard to jurisdictional claims in published maps and institutional affiliations. 